\title{
Formação leitora dos alunos do ensino superior - Análise da construção desse processo
}

\author{
Isabela Quaglia* \\ Cristiane Gonçalves de Aguiar Bonnici** \\ Priscilla Campiolo Manesco Paixão ${ }^{* * *}$
}

\section{Resumo}

\begin{abstract}
A elaboração deste artigo se faz relevante visto que busca conhecer de que forma os alunos do ensino superior estão construindo seu potencial leitor. Sabe-se que a leitura é fonte inesgotável de informação e entende-se que o livro possibilita leituras do mundo e que ela media conhecimentos. Desse modo, este artigo apresenta a reflexão sobre o modo como os alunos se fazem leitores. Para tanto, caracteriza o potencial imaginativo, criativo e argumentativo possibilitado pela leitura. A pesquisa tem como objetivos específicos: caracterizar o processo de leitura de graduandos de um curso e descrever as contribuições dos professores de Língua Portuguesa à apropriação da capacidade leitora. A pesquisa se caracteriza como bibliográfica e traz a análise de uma situação de aprendizagem da linguagem. Como resultado, identifica que o acadêmico de graduação lê pouco e que tem dificuldades de escrita. Aponta que a formação de leitores na graduação requer um trabalho sistematizado com a linguagem durante todo o processo formativo.
\end{abstract}

Palavras-chave: Potencial leitor. Leitura. Formação de leitores na graduação.

\section{Introdução}

A pesquisa sobre a construção da capacidade leitora em acadêmicos de graduação surgiu da experiência das pesquisadoras na área da linguagem. A prática no trabalho com alunos da Educação a Distância despertou a necessidade de observar as dificuldades que os acadêmicos têm com a leitura, o que implica consideravel-

\author{
Recebido: 13/08/2014 - Aprovado: 19/12/2014 \\ http://dx.doi.org/10.5335/rep.v22i1.5191
}

Mestre em Promoção da Saúde. Especialista em Educação a Distância e Tecnologias Educacionais. Docente do Centro Universitário de Maringá. E-mail: isaquaglia@hotmail.com

** Mestranda em Gestão do Conhecimento nas Organizações. Especialista em Formação de Professor de Língua Estrangeira. E-mail: cristiane.aguiar@unicesumar.edu.br

*** Mestre em História pela Universidade Estadual de Maringá (UEM). Especialista em História Econômica pela mesma instituição. Docente do Centro Universitário de Maringá. E-mail: priscilla.paixao@unicesumar.edu.br 
mente na produção textual desses. Sendo assim, a necessidade de entender como se processa a apropriação da capacidade leitora nesses sujeitos faz-se relevante.

A linguagem pode ser interpretada segundo diferentes abordagens teóricas. Para a tradição gramatical grega, ela é vista como expressão do pensamento. Para o Estruturalismo, ela é um instrumento de comunicação e, para o Sociointeracionismo, é considerada uma forma de interação humana. Cada abordagem tem uma maneira de conceber a leitura e a escrita. Na concepção tradicional (linguagem como expressão do pensamento), a leitura não considera a interpretação, é só decodificação do Sistema da Língua.

Os textos trabalhados são os clássicos modelos que o aluno deve seguir. $\mathrm{Na}$ produção de textos, predomina a decodificação da linguagem em itens gramaticais, privilegia-se o como usar as regras gramaticais na produção de textos, na escrita padrão. A estrutura de análise é a frase. Para esta corrente de pensamento:

[...] as pessoas não se expressam por bem porque não pensam. A expressão se constrói no interior da mente, sendo sua exteriorização apenas uma tradução. A enunciação é um ato monológico, individual, que não é afetado pelo outro nem pelas circunstâncias que constituem a situação social em que a enunciação acontece (TRAVAGLIA, 1996, p. 21).

Na concepção de linguagem como instrumento de comunicação, a língua foi conceituada, no Brasil, na década de 1970, "como um código, ou seja, um conjunto de signos que se combinam segundo regras e que é capaz de transmitir uma mensagem, informações de um emissor a um receptor" (TRAVAGLIA, 1996, p. 22).

$\mathrm{Na}$ concepção de leitura, como forma de interação social, terceira concepção de linguagem, o produtor de textos tem como foco um leitor real, escreve para alguém e quer dizer algo. Desse modo, escolhe os recursos da língua que melhor se adequem ao que quer enunciar. Pela leitura, o sujeito se expõe ao mundo, mostra sua subjetividade e a amplia. Mediante a leitura, o escrevente/autor desenvolve as habilidades de ler compreensivamente um texto, compartilha sentidos com aquele que lê o que escreveu, aprende a reconhecer as marcas linguísticas e extrapola a decodificação de símbolos, tem a possibilidade de interpretar e produzir textos nos mais diversos gêneros discursivos. Brandão aponta que:

Uma abordagem que privilegie a interação não pode estudar o texto de forma indiferenciada em que, qualquer que seja o texto, vale o mesmo modo de aproximação. Uma abordagem que privilegie a interação deve reconhecer tipos diferentes de textos, com diferentes formas de textualização, visando a diferentes situações de interlocução (BRANDÃO, 2003, p. 18).

A leitura como ferramenta de atuação social possibilita ao aluno ler, analisar textos, desconstruí-los, adaptar-se a cada situação comunicativa. Na graduação, ele pode e deve ser incentivado a ler diferentes tipos de textos, a diferenciá-los, 
a exercitar a escrita e a entender o funcionamento da linguagem. A formação do hábito de ler é um aprendizado que necessita ser incentivado pelos professores.

Pesquisadores da área da linguagem, como Koch e Elias (2006), Bakhtin (1997) e Alliende e Condemarin (2005), apontam que a leitura é fonte inesgotável de informação. Para esses, o livro possibilita leituras do mundo e a leitura media o conhecimento. Nesse sentido, a presente pesquisa, de caráter bibliográfico, apresenta a reflexão sobre o modo como os alunos se fazem leitores, discute o potencial imaginativo, criativo e argumentativo possibilitado pela leitura, caracteriza o processo de leitura de graduandos de um determinado curso, e descreve as possíveis contribuições dos professores de Língua Portuguesa à apropriação da capacidade leitora.

O professor, com a devida mediação, é responsável pelo processo ensino-aprendizagem e por incentivar seu aluno para que se torne um pesquisador em potencial, que seja crítico e desenvolva-se intelectual e socialmente. De que forma podemos realizar tal tarefa? É simples aplicar as práticas orientadas por pesquisadores, os subsídios teóricos são garantia de sucesso? Neste trabalho, procuraremos analisar estas e outras questões sobre a formação do sujeito leitor.

Para dar consistência à pesquisa, analisamos respostas dadas por acadêmicos de um determinado curso de graduação a uma questão interpretativa na prova de Língua Portuguesa, Leitura, Produção de textos e Literatura Infantil.

A partir dessa análise, pode-se, a priori, constatar que é extremamente grave a falha leitora nos graduandos. Consequência de um histórico de pouco incentivo, de inexistência do hábito de leitura e de um trabalho equivocado dos professores, no ensino médio, sobre a escolha de estratégias adequadas para o trabalho em sala de aula.

\section{A leitura: interação criativa}

Sabe-se que a sociedade ocidental privilegia o ato de ler com uma habilidade que confere cidadania ao ser humano. Aquele que deseja participar ativamente nos grupos sociais necessita saber ler e escrever. Por linguagem entende-se toda manifestação humana que nos constitui como homens. Entende-se que essa maneira de enunciar pode ser oral ou escrita e, que cada uma dessas manifestações do português tem suas particularidades (BRASIL, 1998). Contudo, elas formam um sistema linguístico dinâmico que permeia tudo o que o homem faz.

É pela linguagem que o sujeito socializa saberes, interage, opina, argumenta, se posiciona em sociedade. Esta perspectiva sociointeracionista é apoiada em Koch e Elias (2006), que entendem a leitura como atividade de produção de sentidos, isto é, a cada vez que o sujeito fala, o faz de um contexto, de um lugar, e sua linguagem é 
voltada para um interlocutor e tem uma finalidade. Assim, o acadêmico é um produtor de sentidos, o modo como ele lê ou escreve tem as marcas de sua história.

Por leitura, entende-se o processo de decodificação, interpretação e compreensão de símbolos que nos levam à formulação de uma ideia expressa com propósitos diversos. À medida que os leitores mais experientes vão construindo significados, a partir dessas leituras, tais habilidades tornam-se inerentes, ou seja, atos voluntários que nos permitem entender o texto simultaneamente à decodificação das letras.

Os Parâmetros Curriculares Nacionais - PCNs (BRASIL, 1998) sugerem que o leitor aprenda a interagir mediante os gêneros narrar, relatar, argumentar, expor e instruir, os quais visem às práticas sociais de comunicação, à heterogeneidade de falantes da língua e ao pleno domínio da linguagem.

Alliende e Condemarin apontam que o domínio da leitura implica que o leitor seja "capaz de lembrar-se do que leu, suprir os elementos que não lhe são fornecidos, antecipar fatos e modalidades linguísticas, julgar criticamente os conteúdos" (2005, p. 139).

Essas habilidades não são facilmente adquiridas. Para alcançar tal estágio é preciso uma prática leitora muito bem embasada nas séries iniciais do ensino fundamental. Nela há que se privilegiar textos do conhecimento das crianças, gêneros discursivos presentes em seu cotidiano, como as histórias em quadrinhos. Mas, ao longo dos anos de escolarização, o sujeito deveria entrar em interação com outros textos e desenvolver o gosto de ler. Assim, ao chegar ao ensino superior, teria mais subsídios para o trabalho com textos científicos, próprios da academia.

Baltar et al. (2006) sugerem que o desenvolvimento da capacidade leitora pode ser feito mediante o trabalho com gêneros textuais na perspectiva do Interacionismo sociodiscursivo (ISD), pelo que eles chamam de circuito de gêneros:

O ISD define atividade de linguagem como um fenômeno coletivo de elaboração e prática de circulação de textos, cujo objetivo é estabelecer uma compreensão do contexto e das propriedades das atividades em geral; trata-se de uma meta-atividade que (re) semiotiza as representações humanas no quadro das possibilidades disponíveis de uma língua natural. Quanto à noção de ação de linguagem, o ISD a define como uma parte dessa atividade, cuja responsabilidade é imputada a um ator singular (BALTAR et al., 2006, p. 376, grifo do autor).

Segundo os autores, é possível ao aprendiz da língua portuguesa desenvolver a competência discursiva e o gosto pela leitura, bem social que todos deveriam dominar. Mas a realidade evidencia que muitos acadêmicos chegam à universidade sem saber ler fluentemente, sem gostar de ler, sem ter prazer em conhecer por intermédio dos livros. Muitos apresentam lacunas de formação advindas do ensino fundamental, trazem histórias de práticas de leitura como castigo, como exercício para angariar nota em processos avaliativos. Outros abriram mão da leitura de 
textos escritos para se entreterem com o computador, o celular e outras mídias digitais que utilizam o português com adaptações linguísticas. Nesse sentido, a tecnologia que se mostra, muitas vezes, uma aliada significativa no processo de formação de pessoas, por meio da utilização desproporcional por parte do aluno, acaba por possibilitar um uso indiscriminado dessas adaptações linguísticas. Em muitos recursos tecnológicos, utilizam-se textos relativamente curtos, com abreviações gramaticais de conteúdo, com superficialidade na expressão de ideias, fatores que corroboram para o aluno em formação se acostumar com tal realidade, o que torna a leitura de textos mais elaborados um martírio para esse aluno em toda sua trajetória acadêmica e, consequentemente, em sua vida profissional também.

Os sujeitos, que embora supostamente estejam em situação de autonomia intelectual por estarem no ensino superior, muitas vezes, não sabem a diferença da utilização dos termos linguísticos, desconhecem a análise linguística, assim como o contexto de produção dos textos que estudam na academia. Desse modo, não valorizam o saber que os livros oportunizam em termos de conteúdo e aprendizagem da língua.

Nesta corrente, a leitura que deveria emancipar o sujeito para o pensar e o agir com criticismo, que deveria, através de exercícios e práticas diárias e de busca pelo desenvolvimento intelectual cada vez mais elaborado, transforma-se em uma vilã que só afasta o acadêmico dos ambientes de construção do conhecimento sem permitir interação social. Em meio a esta condição de inimiga que a leitura vai adquirindo ao longo do caminho a comunicação é irremediavelmente afetada

[...] do ponto de vista da dimensão individual de letramento (a leitura como uma "tecnologia"), é um conjunto de habilidades linguísticas e psicológicas, que se estendem desde a habilidade de decodificar palavras escritas até a capacidade de compreender textos escritos. [...] refletir sobre o significado do que foi lido, tirando conclusões e fazendo julgamentos sobre o conteúdo (SOARES, 2002, p. 68-69)

Conforme Soares, a compreensão de textos linguísticos levando a compreensão dos diferentes significados é o propósito primordial da formação de leitores. Com base na decodificação é possível ao ser humano aprimorar sua capacidade de pensar um determinado conteúdo, inferior conhecimentos prévios e abstrair uma significação com uma pluralidade de sentidos impensáveis em outras situações de aprendizagem.

Porém, para se alcançar este nível que certamente passa a ser espontâneo por meio da prática, é necessária uma postura metodológica que requer estratégias e estímulos. Estímulos que deveriam ter sido recebidos antes do ingresso desse indivíduo ao nível superior de ensino. É nessa fase que será exigido desse aluno uma organização de ideias, métodos de leitura e escrita, habilidades e competências 
para ler textos científicos, compreendê-los e certamente produzir outros textos com uma base científica, o que é essencial a qualquer área e a qualquer pesquisador.

Solé (1998) menciona que essa situação é modificada quando o leitor se descobre competente, capaz de compreender o que lê, de entender o que está implícito, de relacionar o texto lido com outros textos,de atribuir sentidos e justificar para outras pessoas sua posição leitora. Entende-se, assim, que o importante no trabalho de formação leitora é a conscientização do adulto sobre seu real papel. O professor de linguagem deve ser uma referência em leitura.

\section{0 professor e a prática leitora}

A aprendizagem da leitura tem estreita relação com a concepção de linguagem do professor. Se ele concebe a linguagem como uma maneira de agir, de dialogar com o outro, sua ação pedagógica frente à leitura privilegiará atividades que partam do texto e que a ele retornem de modo contextualizado. O acadêmico trabalhará com gêneros textuais diversos e aprenderá a função social de cada um deles.

O professor, inicialmente, fará um diagnóstico dos conhecimentos prévios da turma para depois iniciar o trabalho. É importante que o professor tenha clareza de que os estudantes são diferentes, que tem trajetórias linguísticas distintas e que cada um teve ou tem uma relação própria com a língua portuguesa (BALTAR et al., 2006). Por isso, o nível de compreensão dela difere de um para outro. A proposta de circuitos de gêneros:

[...] acaba propiciando um passeio por ambientes discursivos muito diversos, fazendo com que os participantes realizem atividades de linguagem variadas, percebendo as adequações necessárias à sua atuação em cada uma dessas situações sociodiscursivas, modulações tais que constituem etapas da dinâmica de auto-regulagem, potente recurso pedagógico no que tange à conquista de destrezas sociointerativas dos sujeitos envolvidos (BALTAR et al., 2006, p. 282-283).

O trabalho com a leitura é de prazer e alegria. Os textos devem ser escolhidos criteriosamente, tendo em mente o público leitor. O exercício de leitura deve ser gradativo de modo que o acadêmico crie o hábito de ler regularmente, como uma atividade essencial à apreensão do conhecimento. As dificuldades de interpretação e de posicionamento crítico são parte do processo de leitura. O importante é que o acadêmico aprenda a conferir sentido na leitura realizada, que seja capaz de reconhecer os diversos níveis de leitura para apreensão do texto. Segundo Baltar: 
Dominar a maior gama possível de gêneros textuais, orais e escritos, disponíveis no inventário construído sócio-historicamente [sic] contribui para o usuário desenvolver sua competência discursiva, já que é por intermédio dos gêneros textuais que se dá toda a interação sociodiscursiva. A competência discursiva do usuário de uma língua abarca todas essas capacidades, é dinâmica e está em constante desenvolvimento, pois é atualizada a cada momento em que ele participa de uma atividade situada de linguagem, de forma ativa e responsiva $(2006$, p. 379$)$.

Estratégias de como ler e relatar para a classe a ideia principal do texto, apresentar sínteses de textos trabalhados, pesquisar outros textos de um mesmo gênero textual, escrever o que compreendeu e discutir com os colegas aspectos do texto são algumas das possibilidades de aprendizagem da leitura (SOLÉ, 1998).

Sobre os desafios de escolher os textos mais adequados, Travaglia (2002) aponta que ao professor cabe a difícil tarefa de decidir-se por um aparato teórico sobre tipologia textual que dê sustentação ao seu trabalho em sala e, na impossibilidade de trabalhar com a imensidão de textos existentes, fazer a opção por aqueles que instrumentalizarão melhor os alunos a interagirem comunicativamente em sociedade.

Comumente o professor do ensino superior disponibiliza os textos para leitura. $\mathrm{O}$ acadêmico deve fazer uma leitura prévia do material para que possa debater em aula. Contudo, ainda há acadêmicos que não têm o hábito da leitura e esperam que o professor interprete os textos por eles, não realizando nenhum esforço para entender o conteúdo dos textos. Dessa maneira, o contexto de produção do texto, a finalidade desse, a atuação ativa do acadêmico na leitura fica a desejar.

Entende-se com Baltar et al. (2006) que o ideal é que o acadêmico sinta-se responsável por seu processo de formação leitora e que busque compreender reflexivamente o que lê. Sabe-se que entender uma obra na integra não é fácil, mas o exercício de ler cotidianamente oportuniza tal aprendizagem. Ler é uma habilidade que deve ser feita de modo significativo, prazeroso. Ao partir de textos de menor complexidade para os de maior exigência, o professor favorece a formação leitora $\mathrm{e}$ o entendimento dos diferentes tipos de texto.

\section{0 analfabetismo funcional: 0 processo de leitura de graduandos de um curso}

No Brasil, o processo de leitura tem se mostrado ineficiente. A escolarização não tem garantido ao sujeito o domínio pleno da linguagem. Magda Soares (1995) menciona que o termo alfabetização é relacionado por nós, falantes do Português, ao desenvolvimento das habilidades de ler e escrever e que, geralmente, ele aparece associado a um "estado" ou "condição" do sujeito que aprende a língua materna. É, ainda, considerado oposto ao termo analfabetismo. 
O analfabeto é aquele que não domina a escrita da língua que fala. Por infinitas razões, este cidadão não teve oportunidade de frequentar um ambiente escolar ou qualquer outra situação de prática da habilidade de ler e escrever.

Somente recentemente ser alfabetizado significa ler, escrever e adequar esses processos a cada situação de comunicação e cada grupo de convivência, isto é, conhecer a língua, desenvolver técnicas de comunicação capazes de influenciar o outro, identificar os diferentes contextos de enunciação, conhecer as variações linguísticas, identificar e distinguir diferentes textos. Soares apresenta o conceito de alfabetismo englobando:

[...] um conjunto de comportamentos que se caracterizam por sua variedade e complexidade. Uma análise desses comportamentos permite agrupá-los em duas grandes dimensões: a dimensão individual e a dimensão social. Quando se focaliza a dimensão individual, o alfabetismo é visto como um atributo pessoal, referindo-se à posse individual de habilidades de leitura e de escrita. Quando, ao contrário, se focaliza a dimensão social, o alfabetismo é visto como um fenômeno cultural, referindo-se a um conjunto de atividades sociais que envolvem a língua escrita, e a um conjunto de demandas sociais de uso da língua escrita (1995, p. 8, grifos do autor).

Cada uma dessas dimensões tem certa complexidade. Na perspectiva do indivíduo, é preciso considerar as diferenças entre os processos de ler e escrever, entre a decodificação de símbolos e a construção de sentidos para eles, as diferenças individuais, os conhecimentos prévios, a aplicabilidade da linguagem em diferentes produções textuais, e outros. Assim, ser alfabetizado difere de pessoa para pessoa.

Na dimensão social, a alfabetização é vista não como uma condição do ser, mas como uma prática social, importa pensar o que elas fazem com o conhecimento linguístico que adquirem em contextos específicos em que a escrita e a leitura são exigidas.

Outra distinção feita por Soares (1995) é a de analfabeto funcional, termo cunhado pela Unesco em 1978. Entende-se que o analfabeto funcional é aquele sujeito que frequentou uma escola, sabe ler e escrever, então poderíamos caracterizá-lo como alfabetizado. Porém, este leitor, ao se deparar com um texto escrito, somente decodifica os códigos e não compreende o que está contido no texto, ou seja, não interpreta a mensagem. Esse tipo de leitor pode então ser denominado como um analfabeto funcional.

Magda Soares apresenta uma definição sobre o termo alfabetismo e que representa de forma bastante evidente o contraponto entre um e outro:

[...] na verdade, só recentemente este termo (alfabetismo), tem se mostrado necessário porque só recentemente começamos a enfrentar uma realidade social onde não basta somente saber "ler e escrever": Dos indivíduos já se requer não apenas que dominem a tecnologia do ler e do escrever, mas também que saibam fazer uso dela, incorporando-a a seu viver, transformando-se assim, seu "estado" ou "condição", como consequência do domínio desta tecnologia (1995, p. 7). 
Do aluno da graduação espera-se esta potencialidade, que ele seja capaz de não somente decodificar a palavra, mas, sim, ultrapassar isso, mergulhar na compreensão, entender o exposto e fazer uso desse sentido para seu próprio proveito. Essas características fazem parte da sua formação, pois na sua atuação muito se fará uso dessas técnicas para que possa entender o mundo, a sociedade, inferir, criticar, colaborar, enfim, ter uma atitude de maturidade intelectual transformadora da sociedade em que está inserido.

Em uma prova na disciplina de Língua Portuguesa de uma determinada turma foi solicitado o seguinte: Questão: Um clássico ditado popular afirma: "Diga-me com quem andas que te direis quem és”. Fazendo um trocadilho, poderíamos criar um desditado mais ou menos assim: Diga-me, e sabereis quem és. Qual é a interpretação mais adequada desse enunciado?.

As respostas a essa questão variaram de acordo com o conhecimento prévio dos alunos, com as experiências escolares, segundo a conscientização sobre a linguagem e o conhecimento partilhado pelo grupo sobre o conteúdo:

A1 - É através da leitura que identificamos com quem estamos falando. Pois o modo de falar revela quem você e, e através da língua que as pessoas fazem uma analise sobre você, através da comunicação.

A2 - Para mim esta frase indica que se você andar com pessoas é igual a eles.

A3 - As pessoas são analisadas por suas "companias", por estar com alguém não significa que é igual.

A4 - Em uma sociedade só pela maneira de falar já julgamos com preconceitos que nem sempre "e" o real, porque neste pré-conceitos não levamos em consideração os valores culturais que a língua traz.

Os sujeitos A1 e A4 comunicam uma visão de mundo pelo discurso, eles criticam o preconceito linguístico, que tem motivações econômicas e políticas, e apontam a necessidade de captarmos a ideologia da língua, isto é, o nosso falar demonstra como agimos, como pensamos, quem somos. Esse processo nem sempre é consciente, mas existe e exclui as pessoas que não utilizam a maneira socialmente privilegiada.

Koch e Elias (2006) apontam que o sentido do texto é construído a partir da visão de mundo que se tem. No ato de ler, o sujeito interage com o texto e com o produtor dele. Assim, ler exige o desenvolvimento de estratégias, tais como selecionar as informações mais relevantes, antecipar sobre o que o texto tratará (observar o título, se tem imagens) e, ainda, a capacidade de estabelecer relações com o conteúdo lido com base em seus conhecimentos prévios. 
A5 - A nossa sociedade por ser uma sociedade capitalista e ser dividida em classes sociais existem preconceitos capazes de julgar uma pessoa apenas pelas suas companhias sabe-se que em uma sociedade capitalista os grupos são formados pela faixa etária e classes sociais.

A6 - A questão é que hoje em dia ninguém mais se interessa pelo outro e sim consigo mesmo. Muitos acreditam que não dependerão por esse motivo nunca saberemos qual e o verdadeiro interesse das autoridades pela população menos favorecida.

$\mathrm{Na}$ fala citada do respondente A6, é possível notar que a percepção dele da finalidade do texto está relacionada com questões sociais vivenciadas em algum momento de sua vida. Ele cita a falta de interesse pelo próximo e o descaso das autoridades com os menos favorecidos.

A7 - Através do trocadilho o que entendemos e o seguinte. A companhia sendo boa que faca as coisas direito sabe-se que e do bem. Após dizer tudo isto sobre você, seus aspectos positivos ou negativos também sabe-se a seu respeito. A linguagem e a forma de dizer realmente quem somos.

A8 - Quer dizer que se eu andar com um grupo de pessoas chamadas pela sociedade de "bagunceiros" e preguiçosos ou aquilo que eles são, eu também vou levar o credito seja bom ou ruim.

Por sua vez, o respondente A8 relaciona o conteúdo do texto com os tipos de sujeitos existentes. Para ele, há um processo de homogeneização das pessoas em que as características individuais sucumbem às coletivas.

A9 - Ao falar o ser humano demonstra o que esta contido em suas experiências e pelo que dizer o telespectador ou receptor poderá presenciar comportamentos e o próprio se autoanalisar e podendo se auto afirmar no que são para ele essenciais num contexto de observações ou de conexões.

A10 - Todos esses ditados populares são variações lingüísticas que estão presentes na sociedade, pois e uma linguagem que todo mundo fala, ou seja, um padrão presente na comunidade.

Pela análise das respostas, é possível perceber que o grupo de respondentes ora pendeu por relacionar o conteúdo do texto com os tipos humanos, as "companhias" (A2, A3, A5, A7 e A8), ora procurou explicar segundo sua compreensão da linguagem (A1, A4, A6, A9, A10). A linguagem é percebida como prática social historicamente situada na sociedade capitalista, com finalidade de comunicar quem é o homem que enuncia (BRANDÃO, 2003).

Observa-se que as respostas dos alunos evidenciam diferentes percepções sobre a leitura, sobre os gêneros textuais que circulam em nosso meio e a variação linguística, sobre a finalidade dos textos e o contexto de produção de cada um. Cada respondente buscou, em suas experiências prévias com a leitura, uma interpretação possível para o texto em estudo. 


\section{Considerações finais}

Como resultado deste trabalho, identifica-se que os acadêmicos da graduação, que participaram da pesquisa, leem pouco e têm extrema dificuldade de escrita. Destaca-se que a formação de leitores na graduação requer um trabalho sistematizado com a linguagem durante todo o processo formativo, e que o não trabalho dessa habilidade nas séries iniciais agrava ainda mais o problema, tornando-se fator determinante no êxito ou no fracasso escolar.

Das respostas apresentadas pelos alunos na avaliação, analisadas neste trabalho, concluímos que são, na maioria, analfabetos funcionais cuja interpretação de um simples ditado popular torna-se um complexo exercício mental. É certo que se trata de alunos em fase inicial de graduação e que possuem uma longa jornada até o encerramento do seu curso, porém, tristemente, reconhecemos que pouca coisa será alterada se continuarmos com as abordagens já mencionadas e, evidentemente, ineficazes.

De nossa parte, não há como julgar se as respostas estão certas ou erradas, mas compreender que elas se inserem em trajetórias de vida particulares e que, cabe a nós, professores, sugerir estratégias de intervenção pedagógica para auxiliá-los a adequar seu discurso às necessidades de cada contexto.

Se não ouvimos o que gostaríamos quando solicitamos que interpretassem o desditado "Diga-me, e sabereis quem és", temos que ter a sensibilidade e a humildade de trabalhar a sistematização da linguagem com esses acadêmicos, a fim de potencializar sua capacidade leitora.

Pensando na diversidade de gêneros aos quais temos acesso rotineiramente, a sugestão de circuitos de gêneros, que desafiem e estimulem, parece uma estratégia viável. Mais precisamente, trazer os recursos diversos para serem trabalhados dentro no universo escolar, pois somente debater sobre a importância da leitura é pouco, praticar exaustivamente a leitura dentro e fora das salas de aula, mas de forma a desenvolver mais e mais o cognitivo é o que vai nos trazer resultados.

O professor é quem deve refletir sobre quem são seus acadêmicos, sobre o que esses graduandos esperam encontrar, já que não possuem uma real capacidade de reflexão, pois não praticaram o exercício da leitura e, consequentemente, da escrita. É fundamental saber qual a visão de mundo de cada indivíduo para que, como formador, se possa encontrar pistas de como desenvolver esses leitores com o maior poder crítico possível. Retoma-se aqui o que já foi mencionado anteriormente, ou seja, se esse educando se sentir responsável por seu processo de formação leitora, então se encurtará o caminho, pois esse, com autonomia, buscará ampliar mais e mais suas potencialidades. 


\section{Teaching higher education students to read: analysis of the construction of this process}

\section{Abstract}

Current article analyzes the manner students of higher institutions construct their reading potential. Reading is a resourceful source of information and books make possible interpretations of the world mediating knowledge through reading. Reflections are forwarded on how students turn themselves readers. Their imaginative, creative and argumentative potential is made possible through reading. Research aims at characterizing the reading process of undergraduates of a given course and describes the contributions of teachers of Portuguese to the appropriation of their reading capacity. Current bibliographical research analyzes a situation in language learning. Results show that undergraduates do not read much and have great difficulties in writing. The formation of readers in undergraduate courses requires a systematic process with the language throughout the formation period.

Keywords: Reader's potential. Reading. Formation of readers in undergraduate courses.

\section{Referências}

ALLIENDE, Felipe; CONDEMARÍN, Mabel. A leitura: teoria, avaliação e desenvolvimento. 8. ed. Porto Alegre: Artmed, 2005.

BAKHTIN, M. A estética da criação verbal. 2. ed. São Paulo: Martins fontes, 1997.

BALTAR, Marcos; NARDI, Fabiele Stockmans de; FERREIRA, Luciane Todeschini; GASTALDELLO, Maria Eugênia. Circuito de gêneros: atividades significativas de linguagem para o desenvolvimento da competência discursiva. In: Linguagem em (Dis)curso. Universidade do Sul de Santa Catarina. Tubarão: Unisul, v. 6, n. 3, p. 375-387. set./dez. 2006.

BRASIL, Secretaria de Educação Fundamental. Parâmetros Curriculares Nacionais: Língua Portuguesa. Brasília: Secretaria de Educação Fundamental, 1998.

BRANDÃO, H. N. Texto, gêneros do discurso e ensino. In: CHIAPPINI, L. (Org.). Gêneros do discurso na escola: mito, cordel, discurso político, divulgação científica. 4. ed. São Paulo: Cortez, 2003. p. 17-45. (Coleção aprender e ensinar com textos, v. 5).

COLOMER, Teresa; CAMPS, Ana. Ensinar a ler ensinar a compreender. Porto Alegre: Artmed, 2002.

KOCH, I. V.; ELIAS, V. M. Ler e compreender: os sentidos do texto. São Paulo: Contexto, 2006.

SOARES, Magda Becker. Língua escrita, sociedade e cultura. Relações, dimensões e perspectivas. Revista Brasileira de Educação, Caxambu, n. 25, p. 8, out. 1995.

Alfabetização e letramento. 6. ed. São Paulo: Contexto, 2010, p. 68.

SOLÉ, Isabel. Estratégias de leitura. Tradução Cláudia Schilling. 6. ed. Porto Alegre: Artmed, 1998.

TRAVAGLIA, L. C. Concepções de linguagem. In: Gramática e interação: uma proposta para o ensino de gramática no $1^{\circ}$ e $2^{\circ}$ graus. São Paulo: Cortez, 1996. p. 21-22.

. Tipos, gêneros e subtipos textuais e o ensino de língua materna. In: BASTOS, N. B. (Org.). Língua Portuguesa: uma visão em mosaico. São Paulo: Educ, 2002. p. 21-22. 